\title{
Optimization of Microextrusion Preforming Using Taguchi Method
}

\author{
Shao-Yi Hsia \\ Department of Mechanical \& Automation Engineering, Kao-Yuan University, Kaohsiung 821, Taiwan \\ Correspondence should be addressed to Shao-Yi Hsia; syhsia@cc.kyu.edu.tw
}

Received 15 September 2013; Accepted 22 October 2013

Academic Editor: Teen-Hang Meen

Copyright ( 2013 Shao-Yi Hsia. This is an open access article distributed under the Creative Commons Attribution License, which permits unrestricted use, distribution, and reproduction in any medium, provided the original work is properly cited.

\begin{abstract}
Micropin head geometry significantly influences surface contact and electrical conductivity. In this paper, the preforming process of extrusion is investigated to establish it as a viable process for microforming. Here, the numerical simulations using DEFORM3D software are used to examine the effect of preformance and pin shape on the extrusion of microbrass pins with a minimum diameter of $0.88 \mathrm{~mm}$ under several design parameters. These parameters are planned with the Taguchi method and help to discover better conditions for the minimum extrusion loads. For obtaining the required parameters to enable the finite element software, a compression test is first performed to determine the true stress and true strain curve of the materials. The result acquired from the experiment is compared with the simulation outcome and verified the accuracy. The consequences show that the optimal microextrusion forming conditions appear on stage rod length $0.015 \mathrm{~mm}$, extruding angle $60^{\circ}$, upper front-end taper $60^{\circ}$, and bottom stage angle $60^{\circ}$ to minimalize the forming load, and the dimensions of the deformed micropin reveal a good identification with the simulation. The study hence shows a potential tool for the combination of Taguchi method and finite element software to analyze the microforming process in the fastener industry.
\end{abstract}

\section{Introduction}

With the gradually increasing emphasis on microforming and the rapid development of the semiconductor, optoelectronics, communication, and $3 \mathrm{C}$ industries, the direction of product development is towards multifunctions and decreasing of size. For example, parts of common $3 \mathrm{C}$ products like mobile phones, digital cameras, and notebooks are becoming miniaturized, with lightness, thinness, shortness, and smallness all being significant trends. Assembly parts such as microconnectors, micromotor, microsprings, and microgear require the use of microforming as a production and processing technology, where metal forming possesses higher processing efficiency, superior quality stability, and lower costs than other processing technologies. Consequently, the development of new micrometal forming technology continues to be strongly emphasized. Nevertheless, the processing technology for the parts of microsized products is different from it with traditional processing, including the grain size of metal materials, surface friction effect, geometric shape, isotropy of materials, flow stress strain, experimental equipment and the manufacturing of die, and the precise orientation of the relative positions between dies and materials. Moreover, materials with smaller grain sizes appear to have higher hardness and strength after the product being miniaturized to the degree that it is not easily formed. From the aspect of microshaping, materials with smaller grain size can easily fill in small cavity and benefit from the forming of complex microparts. Such an effect is called size effect.

$\mathrm{Wu}$ and Hsu [1] identified the best design parameters using DEFORM-2D to simulate precise bevel gear in 2002 . Appropriate chamfering of corners and tapers could assist materials to flow and decrease forming pressure. Syu [2] used finite element software to analyze axisymmetric forge forming in 2002 and discussed the effects of die parameters on formability. They concluded that die inclination angle and fillet size did not strongly influence forming load but did influence extruded height and width. In the study, larger inclination angle and smaller fillet condition were used to stimulate the extrusion of the larger height and width. Finally, the die inclination angle, reverse fillet radius, and forming strain were represented using a 3D contour map to 
observe the distribution tendency. Chen et al. [3] designed a microterminal component with $0.6 \mathrm{~mm}$ (diameter) $\times 1.0 \mathrm{~mm}$ (depth) $\times 0.125 \mathrm{~mm}$ (inner thickness) and planned five-stage forming (facial dressing, head upsetting, perform, backward extrusion, and size finishing) based on formability of copper alloy in 2005. The finite element simulation software, DEFORM-2D, was further applied to simulate the forming process to provide a reference die design for use in production. The research outcomes demonstrated that lubricant and air easily accumulated in the fillet in a cavity, contributing to unfavorable surface quality of perform fillet after formation. Consequently, such air and lubricant could be excluded by dividing the cavity and adding taper grooves. In terms of die processing, poor processing precision could cause numerous small features $(0.05 \sim 0.1 \mathrm{~mm}$ fillet $)$ in microforming, contributing to unsuccessful forming, centric deviation, and raw edges. More precise processing technology is thus necessary for die processing. Gau et al. [4] discussed size effect with experiments in 2006 and found that the intensity resulted from yield strength and tensile strength of materials and the flow stress and formability of aluminum and copper pole pair could be presented with $T / D$ (plate thickness/average grain size). When $T / D>1$, the yield and tensile strength decreased with decreasing $T / D$, while the yield and bending deviation increased with decreasing $T / D$. Finally, it was indicated that the formability would get worse with decreasing $T / D$ when the plate thickness was not taken into account. With closed dies, $\mathrm{Hu}$ et al. [5] applied finite element analysis to simulating the forge forming of change gears in 2007 that the fillet size would affect the stress and material flow. Focusing on magnesium alloy AZ31, Yoon et al. [6] investigated the effects of various backward extrusion gaps and forward diameter on forward and backward processes at $200^{\circ} \mathrm{C}$ and forecast cracks on the products using the finite element software, DEFORM-2D, in 2008. The research outcomes demonstrated that material tended to flow in the shear direction when outside diameter of the punch head approached the forward diameter and the product cracks were likely to appear on the fillet at the contact between the material and the following channel. Sun et al. [7] utilized the animation simulation and finite element software (DEFORM-3D) for simulating the multistage cold forging of stainless automotive battery fastener backward extrusion process in 2013. In this paper, the CAD drawing was made by Inventor $3 \mathrm{D}$ software, and then the STL file was imported to DEFORM-3D software to do the settings of preprocess and simulation analysis. Effective stress, effective strain, velocity field, and forging force had also been shown in this study. Finally, the actual manufacture measurement results were compared with simulation datum to verify the analysis acceptance. Mori et al. [8] presented the results of experiments conducted to investigate the friction coefficient existing at a brass-steel interface. The research discussed the size effects in friction conditions that exist during microextrusion. In the regime of dimensions of the order of a few hundred microns, these size effects tend to play a significant role in affecting the characteristics of microforming processes. In this study, a series of frictional experiments was conducted using a stored-energy Kolsky bar. Tests were conducted using brass samples of a small grain size
(32 $\mu \mathrm{m})$ and a large grain size $(211 \mu \mathrm{m})$ at low contact pressure $(22 \mathrm{MPa})$ and high contact pressure $(250 \mathrm{MPa})$ to see whether there was any change in the friction conditions due to these parameters. The main conclusion of these experiments was that the friction coefficient did not show any significant dependence on the material grain size, interface pressure, or area of contact. Cao et al. [9] investigated the extrusion process for micropins and its numerical simulation, and the process of extrusion is investigated to establish it as a viable process for microforming. In this paper, the effect of grain size is investigated by using workpieces heat-treated to produce grain sizes varying from $32 \mathrm{~mm}$ up to $211 \mathrm{~mm}$. At the same time, a new method, the Reproducing Kernel Element Method (RKEM), had recently been developed to address the limitations of the FEM (e.g., remeshing issue), while maintaining FEM's advantages. The new RKEM method was used to simulate the micro-extrusion problem and compared with that obtained from the FEM and the experimental result.

Present research on microforming is relatively less in Taiwan. A development technology for developing stabler and rapid micro-metal elements being able to enhance the precision and production efficiency becomes a critical issue. Extrusion is regarded as the commonest metal forming process with deep potential for analyses. This investigation discusses the relevant parameters in microforming pin extrusion, including the effects of die shape on processing. These experimental values are compared with the simulation results.

\section{Research Method and Framework}

2.1. Research Method. Using the finite element software, DEFORM-3D, to analyze the formability, 3D SolidWorks is applied as the platform to simulate forward microextrusion forming and die design (Figure 1). The procedure begins from the production of workpiece. Simple compression tests can obtain the material parameters for simulations and experiments. Finally, the differences are compared. This investigation discusses the effects of various performance geometries and micropin designs (Figure 2) on material filling in forming. During the first stage forming, an angle $(\phi)$ is introduced to the material, and a stage rod length $(h)$ is then extended with end flow to optimize the material filling and decrease the forming load during the second stage forming. Product shape during the second stage forming becomes a front-end taper $(\alpha)$ and bottom stage angle $(\beta)$ shown in Figure 2 for the effects on the filling in the extrusion under different factors and to optimize the design.

2.2. Finite Element Method. Among various methods used in discussions of metal forming, the Finite Element Method is commonly utilized in research analyses. It tends to obtain solutions by simplifying complex problems, such as those involving complex and irregular boundary conditions and loads. As the solutions are merely approximations, rather than accurate solutions, the present numerical solutions are inaccurate. DEFORM-3D, with ordinary application and adaptive geometric shape, exhibits greater practicality 


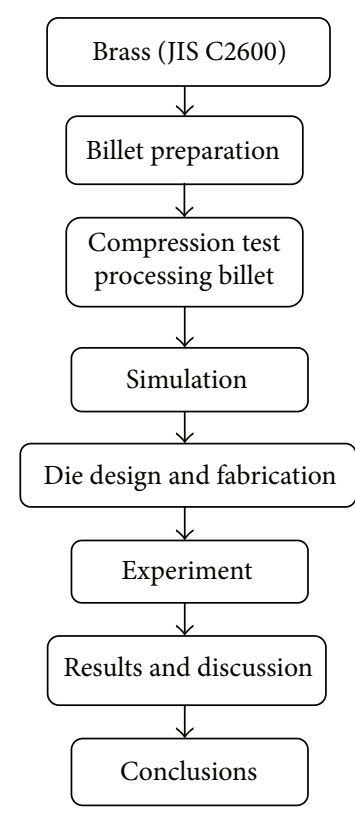

FIGURE 1: Flowchart of study.

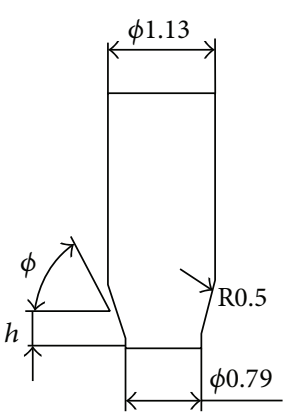

(a) First stage

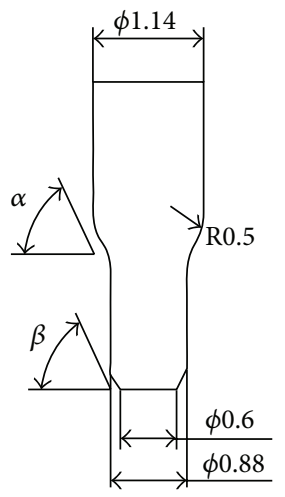

(b) Second stage
FIGURE 2: Key dimensions in preform shape and final product.

and performance advantages in terms of forming load, stress/strain distribution, material distortion, temperature distribution, and velocity field and hence is used in this investigation. The calculation aims to satisfy the equilibrium equation, constitutive equation, geometric compatibility equation, yield criterion, and boundary conditions. Since metal forming is a complicated deforming behavior, the assumption of boundary conditions and material characteristics in Finite Element Analysis being accurate and reasonable would largely affect the analysis results. For simplifying the complexity of plastic processing and reducing the computational time, the suitable assumptions are adopted to analyze in this case. They are listed as below.

(1) The Material Is Assumed to Have the Homogeneity and Isotropy. Cylindrical workpieces are utilized for simulating the microextrusion forming in order to simplify and reduce the analysis complexity. In this study, the workpiece is assumed to be homogeneous and isotropic, but with ignoring the effects of directions that von Mises should be taken into account in the stress yield.

(2) Yield Criterion. Generally, von Mises yielding criterion is adopted as material plastic rule. It provides the relationship between the material yield condition and 3D stress states. All three axial principal stresses can be expressed as the effective stress shown in (1) as

$$
\bar{\sigma}=\frac{1}{\sqrt{2}}\left[\left(\sigma_{1}-\sigma_{2}\right)^{2}+\left(\sigma_{2}-\sigma_{3}\right)^{2}+\left(\sigma_{3}-\sigma_{1}\right)^{2}\right]^{1 / 2}
$$

von Mises presents that the effective stress reaches the yield strength $(Y)$ of material, the plastic deformation occurs. Equation (2) is expressed as

$$
\bar{\sigma}=\frac{1}{\sqrt{2}}\left[\left(\sigma_{1}-\sigma_{2}\right)^{2}+\left(\sigma_{2}-\sigma_{3}\right)^{2}+\left(\sigma_{3}-\sigma_{1}\right)^{2}\right]^{1 / 2}=Y .
$$

(3) Rigid-Plastic Mode. Since the deformation of formed pieces is large in the forming process, the elastic deformation of formed pieces can be ignored but merely considered in the plastic deformation. The upper and the lower molds are assumed as the rigid body, which will not deform because of pressure. The variation principle of von Mises is used as the finite element for the rigid-plastic material, and the functional is shown as follows [10]:

$$
\pi=\int_{V} \bar{\sigma} \dot{\bar{\varepsilon}} d V-\int_{S_{F}} \bar{t}_{i} v_{i} d S,
$$

where the equivalent strain rate is the surface force. The first variation of the functional is acquired by the basic finite element as

$$
\delta \pi=\int_{V} \bar{\sigma} \delta \dot{\bar{\varepsilon}} d V+k \int_{V} \dot{\varepsilon}_{V} \delta \dot{\varepsilon}_{V} d V-\int_{S_{F}} \bar{t}_{i} v_{i} d S,
$$

where $k$ is the penalty constant and $\dot{\varepsilon}_{V}$ is the volumetric strain rate.

(4) Constant Temperature Mode. The forming temperature is kept at the room temperature, and the temperature resulted from the plastic deformation of formed pieces in the cold forming process is small than the effects of the local temperature which is ignored [11].

(5) Friction Model. The cold forming processing of fasteners reveals high contact pressure that the constant shear friction model is utilized for the interface friction, the constant shear friction factor is regarded as the interface friction coefficient, and the interface friction between the mold and the work remains constant in the process.

2.3. Stress-Strain Curve. To enable the finite element software, DEFORM, to simulate forward microextrusion, simple compression tests are first performed to determine the true stress-true strain curve of the materials. Electric press, with compression function, is used to perform the tests. 
The maximum force of the punch head is $5,000 \mathrm{Kg}$, with $1 \%$ error (JP-5400). The simple compression test sheet is implemented using ASTM E9-89 rules, with the diameterheight ratio of $2: 3$. The compression rate for the tests is $0.01 \mathrm{~mm} / \mathrm{s}$, and the brass pin applies to diameter $1.1 \mathrm{~mm}$ and height $1.65 \mathrm{~mm}$. The upper and lower flat dies are used for the compression tests, in which the material for the flat die is SKD11 with heat processing and burnishing processing. Molybdenum disulfide $\left(\mathrm{MoS}_{2}\right)$ grease is added to reduce the friction effect. The sheet is compressed to $90 \%$ depth to enable the grease to evenly flow out on sheet compression. In this case, the contact surface of the die is determined through favorable interface lubrication, and the load-displacement curve during compression is then obtained using a computer to calculate the true stress-strain curve. The equations of true stress and true strain are shown as follows:

$$
\begin{gathered}
\sigma=\frac{F}{\left(\pi \times D \times H_{0}\right) / H} \\
\varepsilon=\ln \left(\frac{H_{0}}{H}\right),
\end{gathered}
$$

where $\sigma$ is the true stress, $F$ the punch load, $D$ the pin diameter, $H_{0}$ the pin original height, $H$ the pin compressed height, and $\varepsilon$ the true strain.

2.4. Simulation of Forward Microextrusion. When the finite element software, DERORM-3D, is used to simulate forward microextrusion of workpiece, the differences between the simulated stage process and the experimental process are discussed, and the reaction of the punch head when the effective stress strain, material flow, and simulated estimated materials result from the extrusion forming is assessed for the standard of punch head and die intensity during die design. DEFORM-3D is applied to simulate the forward extrusion of brass (C2600). Since the forming is axisymmetric, the model is merely $1 / 6$ constructed, appropriate boundary conditions are set, rigid plastic is used for the work, the total grid number for the finite element is approximately 15,000 , the punch head speed is $0.12 \mathrm{~mm} / \mathrm{s}$, and the friction factor between objects is 0.12 . A brief summarization of the analysis conditions is denoted in Table 1, and the simulation steps are shown as follows. (1) SolidWorks is utilized for drawing the required die (cavity, upper punch, and lower ejector), which is further transformed into STL files. (2) The STL files are imported into DEFORD 3D, the punch head and die are set on the suitable positions shown in Figure 4 and the grid division is defined. (3) The true stress-strain curve obtained from compression tests shown in Figure 3 is regarded as the basis of the material character. (4) The compression stroke and the punch head speed are defined. (5) The friction between objects applies to constant friction factor.

\subsection{Taguchi's Optimization Experiment}

(1) Taguchi's Orthogonal Array. Taguchi's Orthogonal Array describes the creation of a pair of parameters from all levels at two column intervals in the experimental table, where each composition presents the same frequency. The Classical
TABLE 1: Analysis conditions in FEM simulation.

\begin{tabular}{lc}
\hline Workpiece & Brass (JIS C2600) \\
Flow stress & $\sigma=721.46 \varepsilon^{0.4606}$ \\
Workpiece/die & Rigid plastic body/rigid body \\
Symmetric mesh & $1 / 6$ \\
Mesh number & $10,000 \sim 15,000$ \\
Punch speed $(\mathrm{mm} / \mathrm{sec})$ & $0.1 \mathrm{~mm} / \mathrm{sec}$ \\
Frictional factor & Constant frictional factor/0.12 \\
\hline
\end{tabular}

Orthogonal Array is named after $L_{a}\left(b^{c}\right)$ and presents that the experiment contains $c$ factors, each of which has $b$ levels for an experiment. Orthogonal Array compromises on experimental cost and precision, and fewer experiments are needed to achieve useable statistical information. Nevertheless, Orthogonal array experiments are not full factorial experiments. The "bias" cannot be completely eliminated, but is acceptable as not all levels of compositions appear on the orthogonal array. The optimal composition therefore might not be in the experimental group.

(2) Signal-to-Noise Ratio ( $S / N$ Ratio). $S / N$ ratio is often used as the quality index in the Taguchi method, showing the effects of errors on the process or product level. According to different quality characteristics, various $S / N$ ratio formulas would appear, including nominal-the-best, smallerthe-better, and larger-the-better. Only smaller-the-better is applied in this study for the minimum extrusion loads, where smaller-the-better $S / N$ ratio is shown as follows:

$$
S / N_{\mathrm{SB}}=-10 \log \left[\frac{\sum_{i=1}^{n}\left(y_{i}\right)^{2}}{n}\right],
$$

where $y_{i}$ presents the experimental values, and $n$ the number of experimental times.

(3) Factor Response Table. The response table and response diagram of each factor are constructed after the experiment for understanding the effects on the target function. Based on the $S / N$ ratio of each factor in the same level to calculate the mean, the effects of the factor level on the results are listed in a table and transformed into an auxiliary response diagram as

$$
M_{i j}=\frac{\sum_{k=1}^{N} S / N_{i j k}}{N},
$$

where $M_{i j}$ is the mean $S / N$ ratio of the experiment with $i$ factor and $j$ level, $k$ the $k$ th $S / N$ ratio with $i$ factor and $j$ level, and $N$ the number of experiments with $i$ factors and $j$ level.

A number of simulations are planned with the Taguchi method in designing the geometric of optimal microextrusion dies for discovering the better conditions for the minimum extrusion loads.

\section{Simulation and Experiment}

3.1. FEM Simulation. By following Table 2 planned with the Taguchi method, an angle $(\phi)$ and rod length $(h)$ are used to 


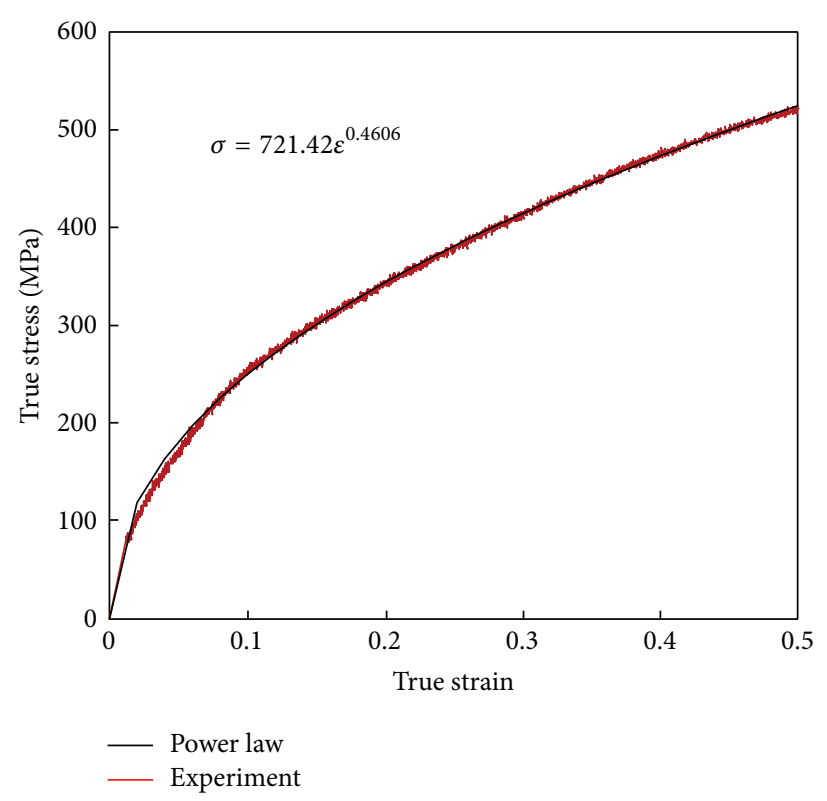

(a) True-stress and true-strain curve
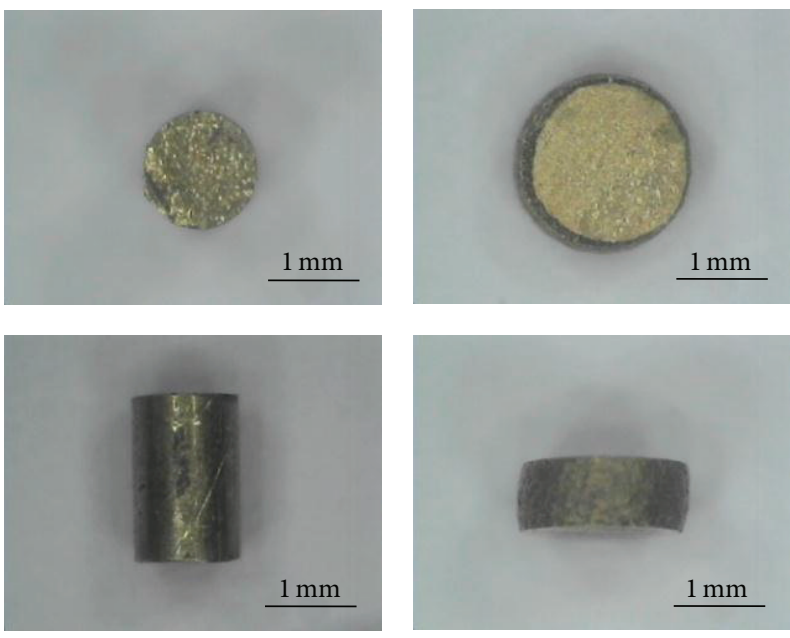

(b) Original and deformed brass pin

FIGURE 3: Simple compression tests of the material.

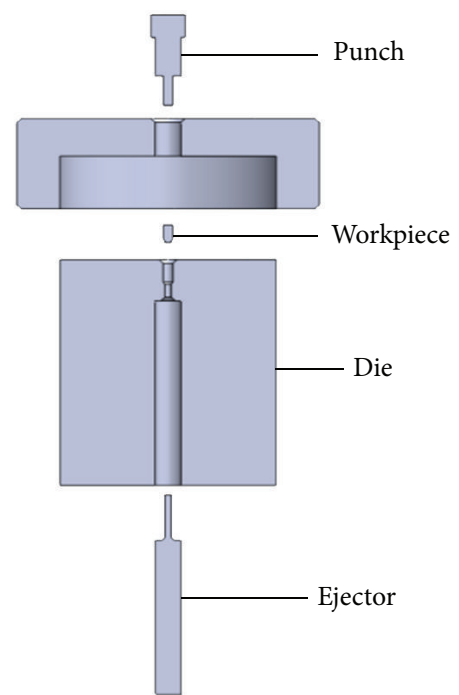

FIGURE 4: Schematic diagram of die construction.

design the first stage forming, and a front-end taper $(\alpha)$ and bottom stage angle $(\beta)$ are used for the second stage forming. All of the four factors have three levels and will be used to discuss the effects on the filling in the extrusion under different factors and to optimize the design. To simplify the simulation quantity, 9 sets of Taguchi's orthogonal arrays $L_{9}\left(3^{4}\right)$ are applied to acquiring the minimum extrusion loads. Consequently, based on $S / N$ ratio, response table or response diagram can hence be utilized for finding the optimal designing conditions.

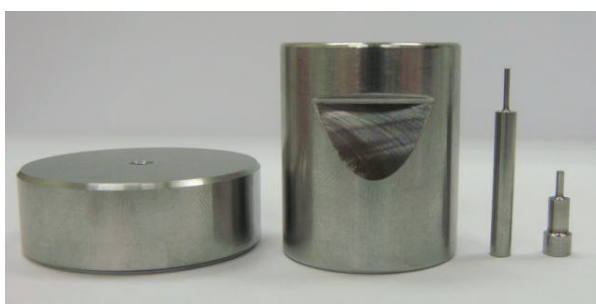

Figure 5: Die components.

TABle 2: Die parameters and factors of Taguchi method.

\begin{tabular}{lcccc}
\hline Factors & Specifics & Level 1 & Level 2 & Level 3 \\
\hline A & $h$ (mm) & 0.05 & 0.1 & 0.2 \\
$B$ & $\phi$ (Deg.) & 45 & 50 & 60 \\
C & $\alpha$ (Deg.) & 45 & 60 & 75 \\
$D$ & $\beta$ (Deg.) & 0 & 30 & 60 \\
\hline
\end{tabular}

3.2. Die Design and Experiment. This study designs forward microextrusion die (Figures 4 and 5). By locating a punch head in the cavity, the movement uses a plate to extrude the punch head, the materials are formed into the required shape, and the product is ejected. The orientation of the punch head and cavity can be ignored. The die components include the punch head, upper module, cavity, and ejector. The punch head has diameter $1.13 \mathrm{~mm}$, with SKH9 high-speed steel as the material; JIS SKD 11 is selected as the material of the upper module and guides the positioning of the punch head and cavity; the tungsten carbide (WC) module is embedded in the cavity, where the tungsten carbide module is subjected to inward stress to offset the outward stress on the cavity during 
forging so as to reduce the overall stress and improve die life; the tool steel, JIS SKD11, strengthened by heat processing is used for the rest of the forms; SKH9 is selected for the ejector, which displays both ejection and forming effects.

The completed die is installed on the electric press platform for a microextrusion forming experiment. The experimental load and stroke data are obtained via an interface and recorded on a computer. The experimental procedure used in micropin forming is as follows (Figure 4). (a) The cavity is placed on the lower module and takes the form of a composite cavity. (b) The workpiece is evenly covered with lubricant and located in the cavity. (c) The upper module corresponds to the cavity. (d) The punch head is located on top of the workpiece and oriented with the cavity. (e) The press stroke is calculated and the data are obtained.

\section{Results and Discussions}

By simulating the forming punch head of a brass micropin with minimum diameter $0.88 \mathrm{~mm}$, the effects of performance design and pin shape on the cavity extrusion filling under different factors are experimentally verified. The first forming stage aims to extrude angle $(\phi)$ on the workpiece with forward extrusion and to extend a stage rod length $(h)$ to improve material filling and reduce forming load during the second forming stage. During the second stage, the geometric shape of the product is changed to an upper front-end taper $(\alpha)$ and the bottom stage angle $(\beta)$, and the effects on filling during extrusion forming are discussed, under the factors, for design optimization.

According to Taguchi's orthogonal array $L_{9}\left(3^{4}\right)$, nine experiments and nine different symbols represent each simulation result. On Table 2, the workpiece is extended in the stage rod lengths $(h), 0.05 \mathrm{~mm}, 0.1 \mathrm{~mm}$, and $0.2 \mathrm{~mm}$, and extruded with the angles $(\theta), 45^{\circ}, 50^{\circ}$, and $60^{\circ}$. Regarding the design of second forming stage, the angles $\alpha$ and $\beta$ are changed to simulate the filling differences with restricted forming load, where $\alpha$ is conducted with $45^{\circ}, 60^{\circ}$, and $75^{\circ}$, and $\beta$ is also conducted with $0^{\circ}, 30^{\circ}$, and $60^{\circ}$. Table 3 represents the DEFORM-3D simulation results of forming loads and smaller-the-better $S / N$ ratio according to (6). Table 4 shows the factor response table of $S / N$ ratio on forming loads, which was calculated from the simulation results in Table 3. The level values listed under column present the effects of variability, and the variability among different levels could be regarded as the effect of controlling factors on $S / N$. The range in the table shows the maximum range of variability, where the larger variability in rank is more important in the design optimization. Hence, Table 4 shows that stage rod length $(h)$ is the largest factor in the experimental results, followed by bottom stage angle $(\beta)$, upper front-end taper $(\alpha)$, and extruding angle $(\phi)$. As the $S / N$ ratio is expected to be smaller-the-better, the optimal experimental settings for minimum extrusion load showed the conditions of A1B3C2D3. This implies stage rod length $0.015 \mathrm{~mm}$, extruding angle $60^{\circ}$, upper front-end taper $60^{\circ}$, and bottom stage angle $60^{\circ}$. The quality characteristics shown in Figure 6 are the response graph according to Table 4, where

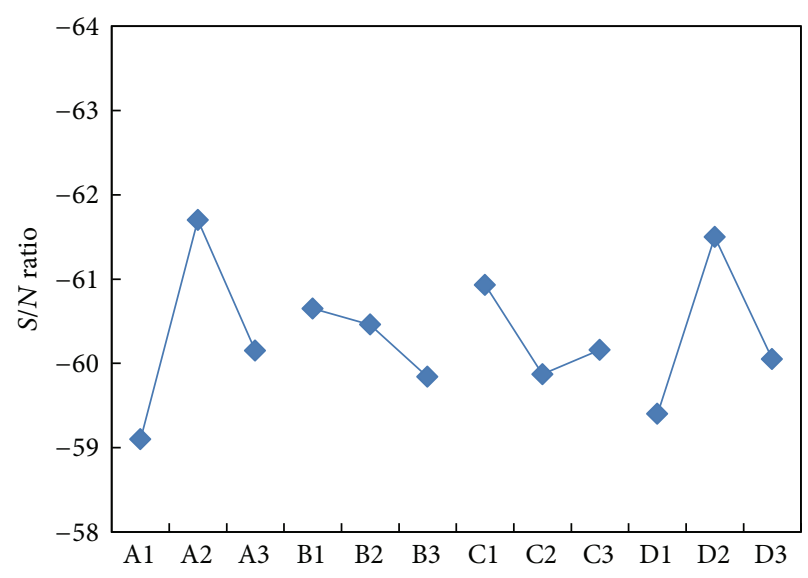

Figure 6: The response graph of $S / N$ ratio in different levels.

TABLE 3: Simulation layout and results using the modified $L_{9}\left(3^{4}\right)$ orthogonal array.

\begin{tabular}{lcccccc}
\hline Set & A & B & C & D & Loads (N) & $S / N$ \\
\hline 1 & 1 & 1 & 1 & 1 & 904 & -59.12 \\
2 & 1 & 2 & 2 & 2 & 998 & -59.98 \\
3 & 1 & 3 & 3 & 3 & 812 & -58.19 \\
4 & 2 & 1 & 2 & 3 & 1165 & -61.33 \\
5 & 2 & 2 & 3 & 1 & 1092 & -60.76 \\
6 & 2 & 3 & 1 & 2 & 1415 & -63.02 \\
7 & 3 & 1 & 3 & 2 & 1190 & -61.51 \\
8 & 3 & 2 & 1 & 3 & 1077 & -60.64 \\
9 & 3 & 3 & 2 & 1 & 823 & -58.31 \\
\hline
\end{tabular}

the $x$-axis Al represented the reaction with controlling factor A and level number 1 . The $y$-axis represented the $S / N$ ratio of forming load. The notation in this figure is similar with that in Table 4. It means that $\mathrm{A}$ and $\mathrm{D}$ are significant factors, and $B$ and $C$ have light influence on a number of simulations. Figure 7 indicates the effective stress, effective strain, and velocity of the workpieces on the different forming series. The maximum valves of effective stress and strain always occur on the corner or bottom of the deformed micropins. As shown in Figure 7, there are the two maximum effective stresses 1,600 MPa on stage 1 and 1,800 MPa on stage 2 due to a larger deformation. The similar tendency is also obtained on the maximum effective strains 5.3 and 6.4 for different stages. The corresponding microstructures of the second deforming stage on the top right corner, middle right corner, and bottom right corner are shown in Figure 8. These microstructures are obtained by metallographic test on 100 times and 200 times. Due to the lager deformations on middle and bottom corners, the grain shapes of the two positions became long and narrow. It is opposite to the top side that seems to have a nearly original grain shape. The figure also denotes that the deforming tendency of the middle right corners is counterclockwise corresponding to the velocity fields shown in Figure 8. 
Stress-effective (MPa)
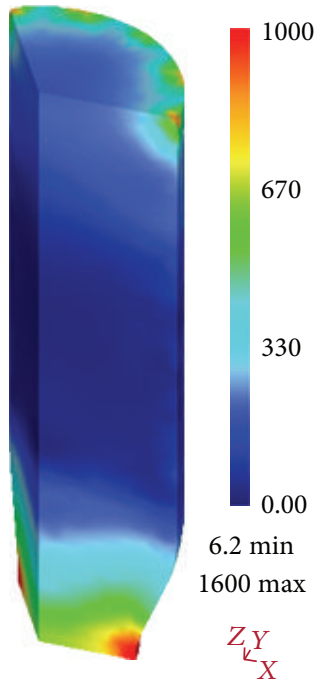

Stress-effective (MPa)

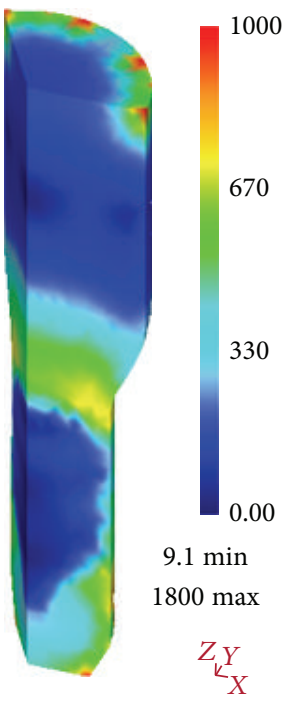

Strain-effective $(\mathrm{mm} / \mathrm{mm})$
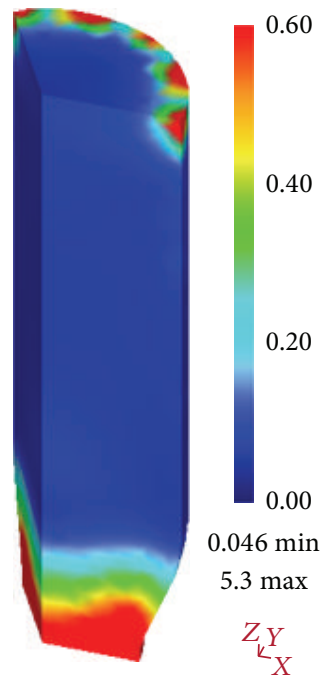

(a) First stage

Strain-effective $(\mathrm{mm} / \mathrm{mm})$

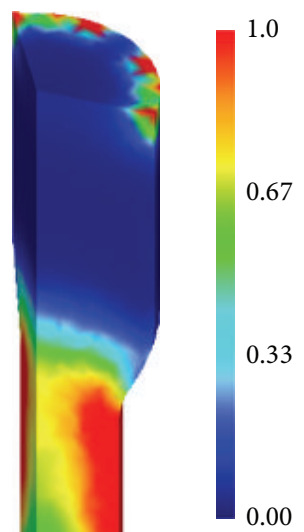

$0.017 \mathrm{~min}$

$6.4 \max$

$Z_{k_{X}}$
Velocity-total vel ( $\mathrm{mm} / \mathrm{s})$

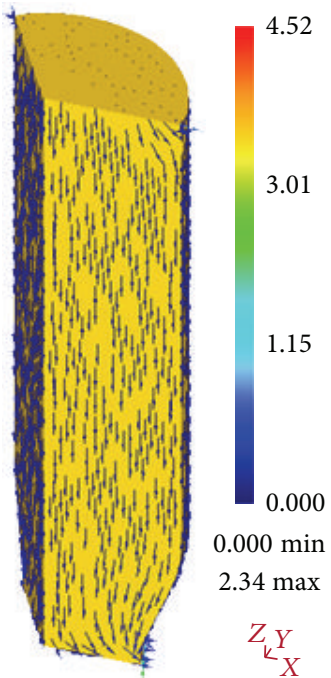

Velocity-total vel $(\mathrm{mm} / \mathrm{s})$

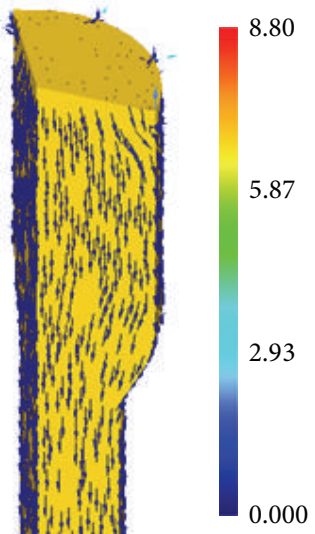

$0.000 \mathrm{~min}$

$2.96 \max$

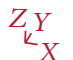

(b) Second stage

Figure 7: Stress-effective, strain-effective, and velocity of extrusion in 3D.

TABLE 4: Response table of punch load in different levels of $S / N$ ratio.

\begin{tabular}{lcccc}
\hline & $\mathrm{A}$ & $\mathrm{B}$ & $\mathrm{C}$ & $\mathrm{D}$ \\
\hline Level 1 & -59.10 & -60.65 & -60.93 & -60.05 \\
Level 2 & -61.70 & -60.46 & -59.87 & -61.50 \\
Level 3 & -60.15 & -59.84 & -60.16 & -59.40 \\
Range & 2.60 & 0.82 & 1.06 & 2.10 \\
Rank & 1 & 4 & 3 & 2 \\
\hline
\end{tabular}

Comparison of the simulation and experimental results shown in Figure 9 reveals no significant difference. Table 5 shows mean and standard deviation (SD) values on the basis of three micropins for second stage. In this table, two diameters $1.14 \mathrm{~mm}$ and $0.88 \mathrm{~mm}$ and four measurement positions of the deformed micropin are used to verify the satisfactory results. All SD values are from 0.001 to $0.006 \mathrm{~mm}$. When considering the relations of stroke load, Figure 10 indicates the situation of the two stages in three cases: the experiment result, the simulation of the rigid die, and the elasticplastic die. Although the simulation load would suddenly rise when die is set as a rigid body, which is different from the experimented forming load, they always have the same tendency. When the die cavity is filled with the raw material, the increased drag force quickly induces the major stroke load in all cases. As a result, Figure 10 implies that the die is set as a 
TABle 5: Dimensions of the deformed micropin.

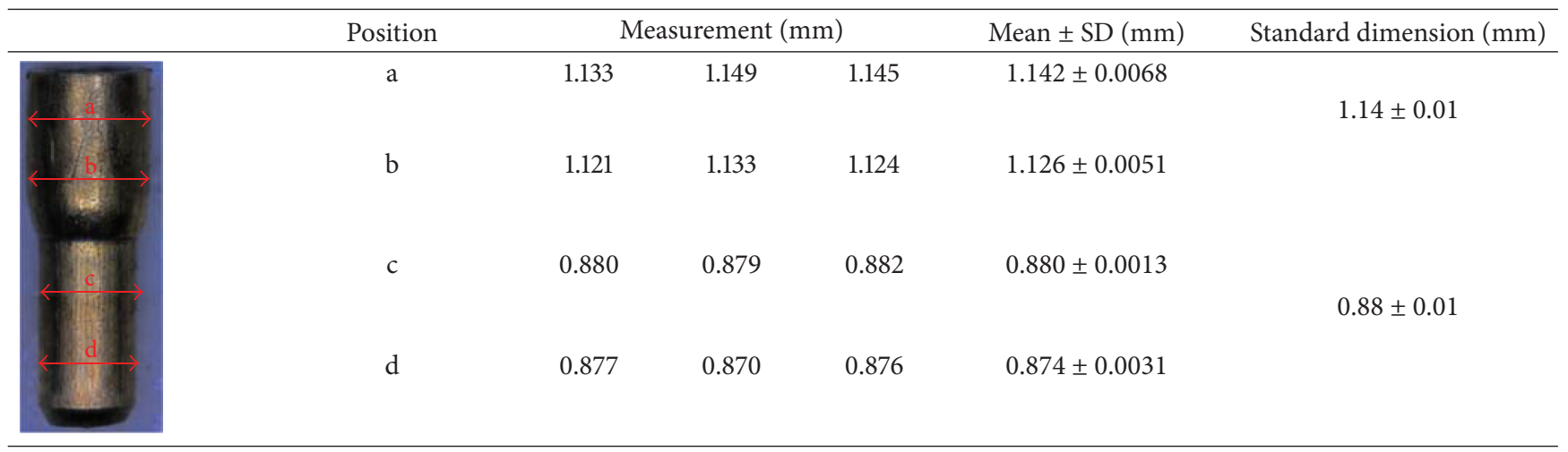

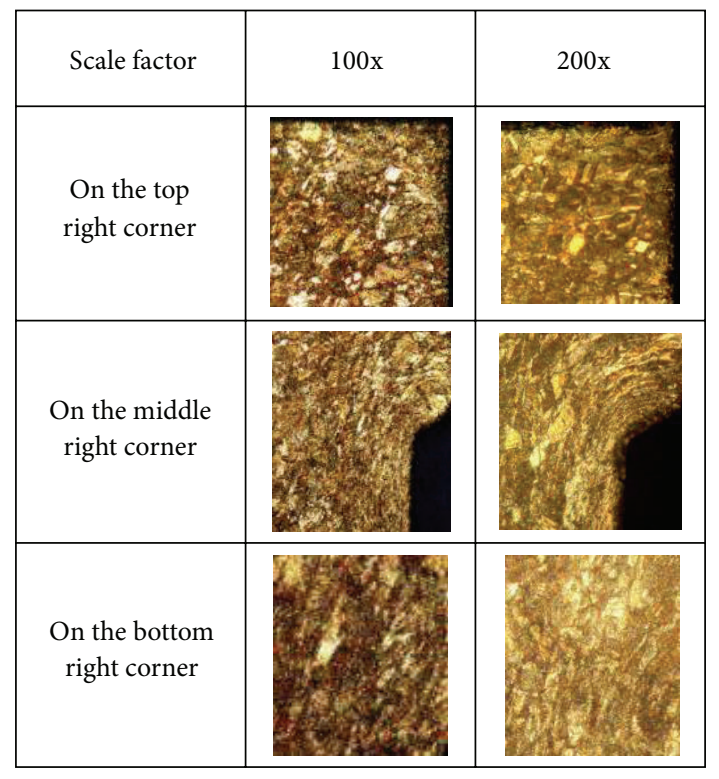

FIGURE 8: Microstructure of deformed brass sample.

flexible body in the simulation, and the simulated stroke-load tendency is close to the experimental result.

\section{Conclusion}

This study simulates the forming punch head of brass micropin with minimum diameter $0.8 \mathrm{~mm}$. Under various factors, the effects of performance design and pin shape on cavity extrusion filling are experimentally verified. The process is completed using two-stage forming. The first stage, performance of forming, produces a stage rod with a workpiece through forward extrusion. The second stage then completes the cavity filling. Besides performance, namely, the design of stage rod, the effects of pin shape on the process are also considered. The research outcomes are summarized below.

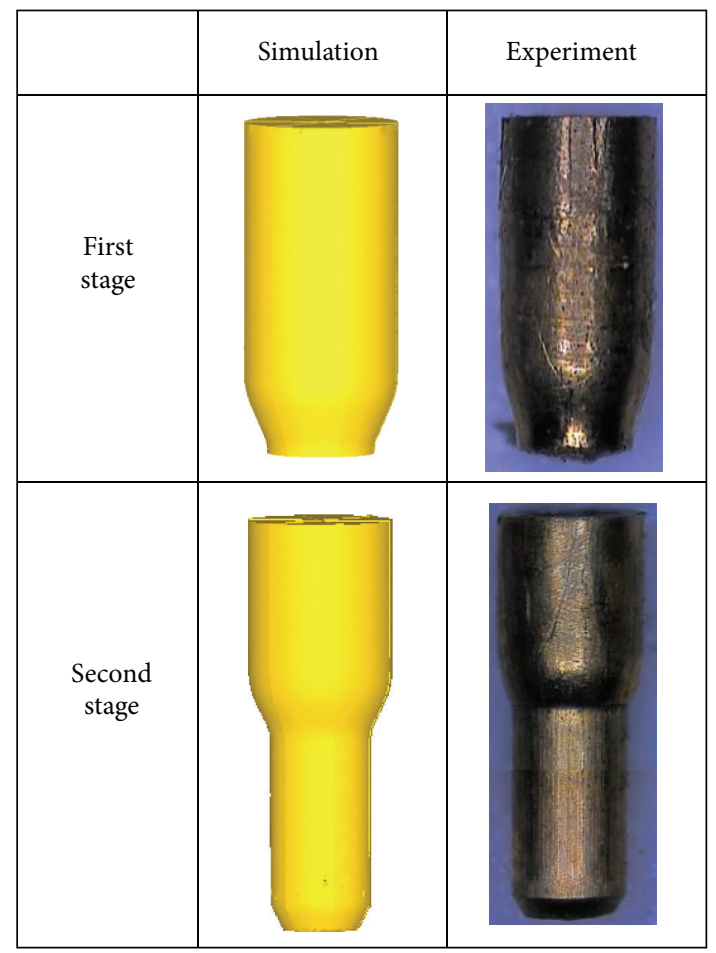

FIGURE 9: Predicted results and extruded products $(h=0.05 \mathrm{~mm}$, $\phi=60^{\circ}, \alpha=60^{\circ}$, and $\beta=60^{\circ}$ ).

(1) This study shows a potential tool on the combination of Taguchi method and DEFORM-3D software to simulate the microforming process.

(2) The stage rod length is the largest factor in the experimental results, followed by bottom stage angle, upper front-end taper, and extruding angle.

(3) The forming conditions of optimal microextrusion appear on stage rod length $0.015 \mathrm{~mm}$, extruding angle $60^{\circ}$, upper front-end taper $60^{\circ}$, and bottom stage angle $60^{\circ}$.

(4) The dimensions of the deformed micropin reveal a good identification with the simulation. 


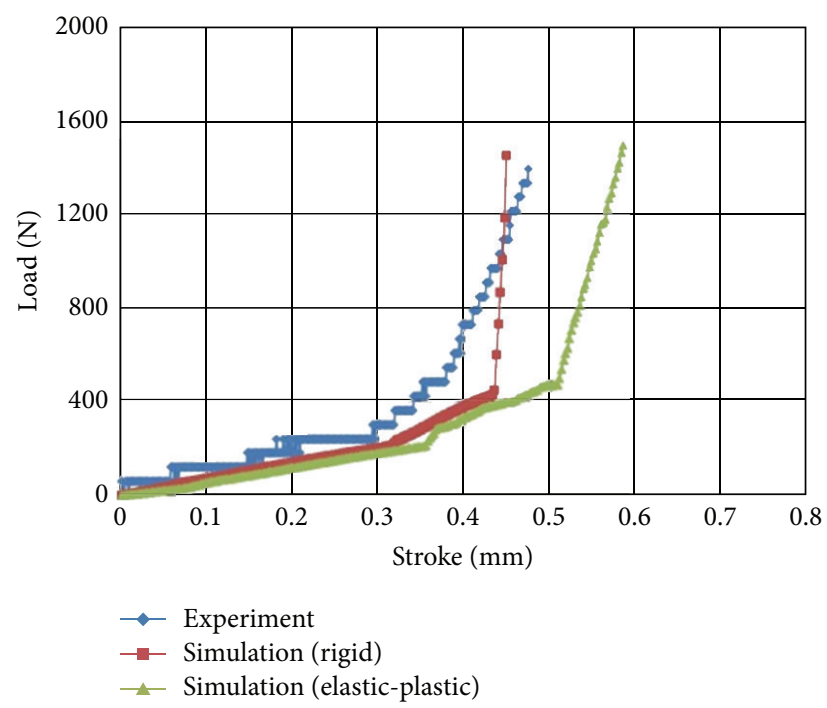

(a) First stage

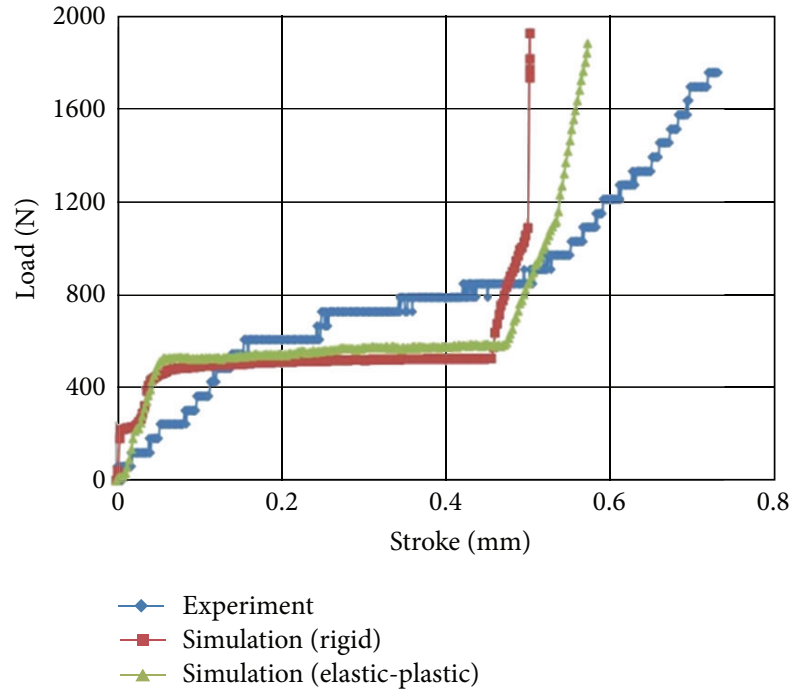

(b) Second stage

FIGURE 10: Predicted and measured loads.

Satisfactory results are obtained in this research. It hence proposes a good analysis technology to manufacture successfully the microsized fastener for the industry.

\section{References}

[1] C.-Y. Wu and Y.-C. Hsu, "The influence of die shape on the flow deformation of extrusion forging," Journal of Materials Processing Technology, vol. 124, no. 1-2, pp. 67-76, 2002.

[2] H. S. Syu, "A study on precision forging of bevel gear by using finite element method," Report on the outcome of the National Science Council Research Project, 2003.

[3] Y. A. Chen, C. F. Wu, and H. C. Tsai, "The development of the micro terminal of battery con-tact device for mobile phone," Forging, vol. 13, pp. 52-57, 2004.

[4] J.-T. Gau, C. Principe, and J. Wang, "An experimental study on size effects on flow stress and formability of aluminm and brass for microforming," Journal of Materials Processing Technology, vol. 184, no. 1-3, pp. 42-46, 2007.

[5] C. Hu, K. Wang, and Q. Liu, "Study on a new technological scheme for cold forging of spur gears," Journal of Materials Processing Technology, vol. 187-188, pp. 600-603, 2007.

[6] D. J. Yoon, S. J. Lim, H. G. Jeong, E. Z. Kim, and C. D. Cho, "Forming characteristics of AZ31B magnesium alloy in bidirectional extrusion process," Journal of Materials Processing Technology, vol. 201, no. 1-3, pp. 179-182, 2008.

[7] M.-C. Sun, G.-Y. Tzou, and L.-A. Zheng, "Processing animation simulation and FEM analysis of multi-stage cold forging of stainless automotive battery fastener," Indian Journal of Engineering \& Materials Sciences, vol. 20, pp. 219-224, 2013.

[8] L. F. Mori, N. Krishnan, J. Cao, and H. D. Espinosa, "Study of the size effects and friction conditions in microextrusion-part II: size effect in dynamic friction for brass-steel pairs," Journal of Manufacturing Science and Engineering, vol. 129, no. 4, pp. 677689, 2007.

[9] J. Cao, N. Krishnan, Z. Wang, H. Lu, W. K. Liu, and A. Swanson, "Microforming: experimental investigation of the extrusion process for micropins and its numerical simulation using RKEM," Journal of Manufacturing Science and Engineering, vol. 126, no. 4, pp. 642-652, 2004.

[10] K. H. Huebner and E. A. Thornton, Finite Element Method, Hsiao Yu-an Publishing, Taipei, Taiwan, 1984, translated by C.C. Wang.

[11] S. Isogawa, I. Mori, and Y. Tozawa, "Determination of basic data for numerical simulation," The Japan Society for Technology of Plasticity, vol. 38, no. 5, pp. 480-485, 1997. 


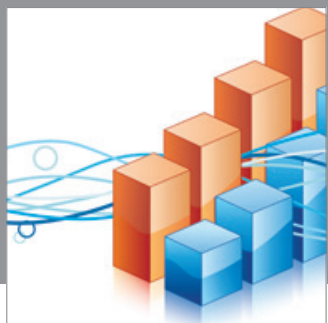

Advances in

Operations Research

mansans

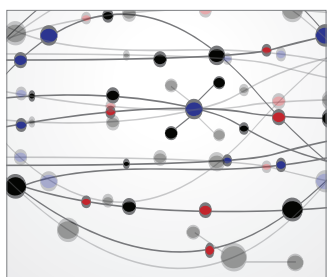

The Scientific World Journal
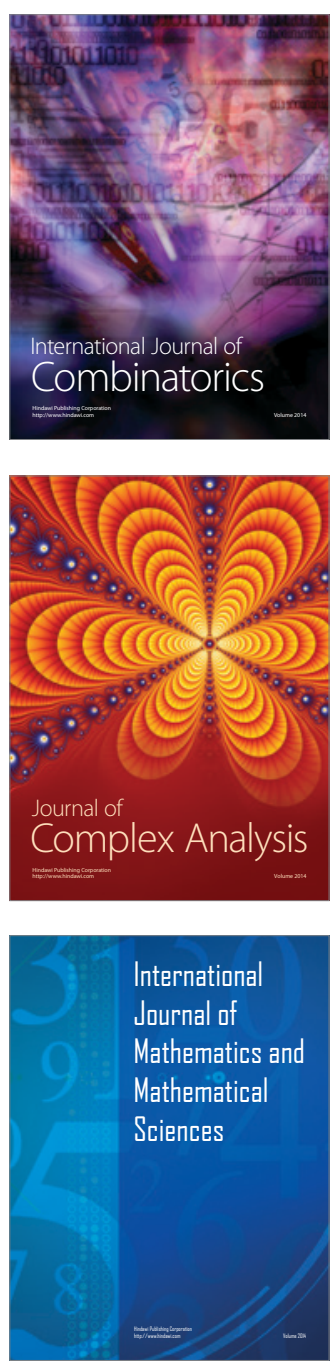
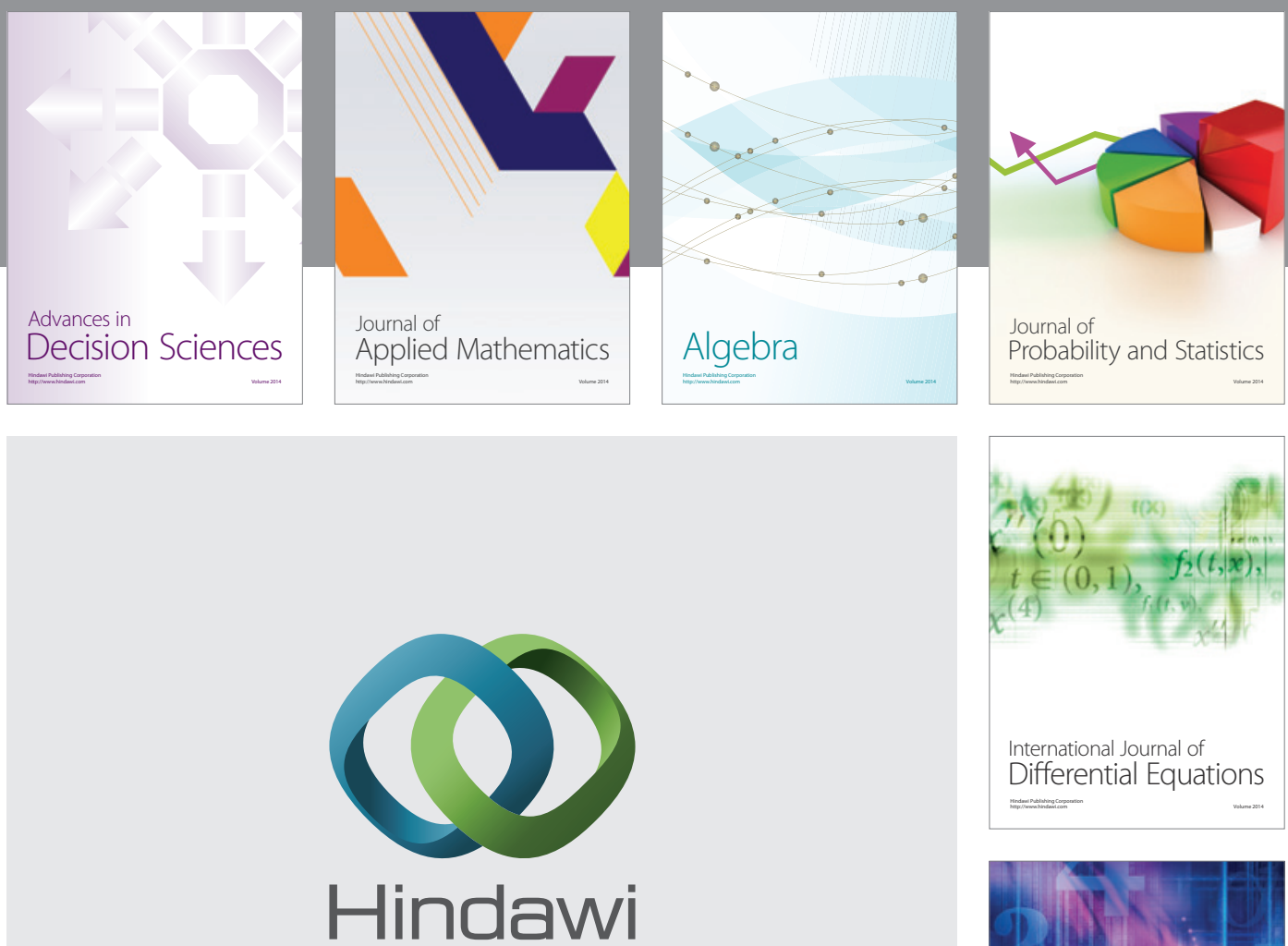

Submit your manuscripts at http://www.hindawi.com
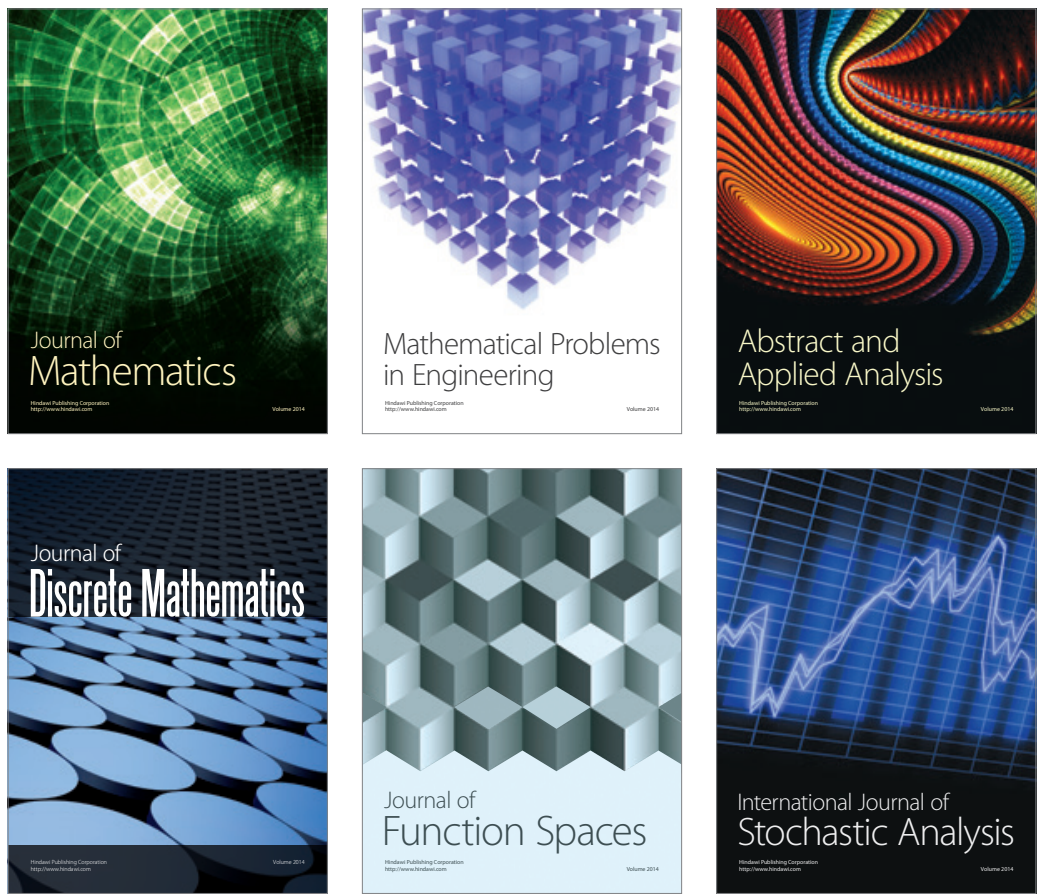

Journal of

Function Spaces

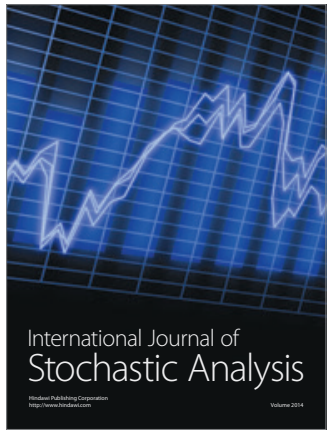

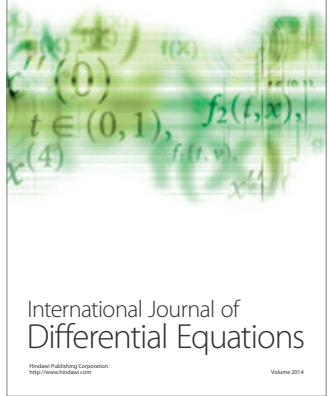
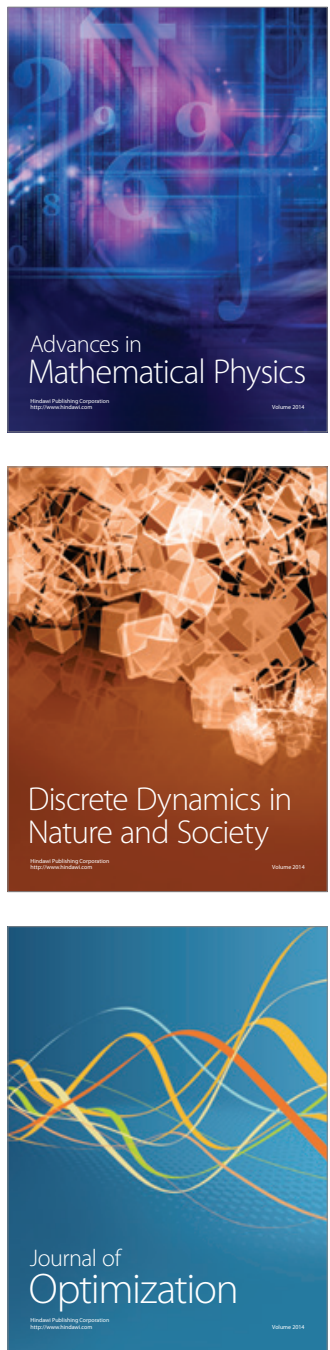